\title{
Dos notas sobre el Noti
}

DOI: 10.5821/palimpsesto.15.4812

Con motivo del reciente centenario del nacimiento de Josep Maria Sostres y del medio siglo de vida de su edificio para El Noticiero Universal, recuperamos dos textos de los profesores Coque Bianco $y$ Carles Martí Arís publicados en 1980.

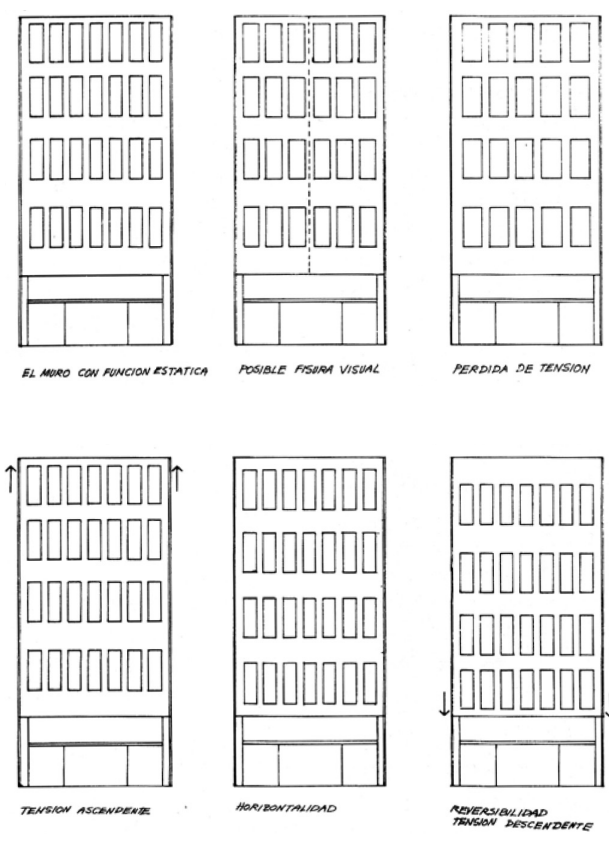

Serie gráfica ilustrativa de diferentes posibilidades compositivas variando la cantidad de ventanas, su tamaño y situación en el plano de la fachada comparándolas con la opción de
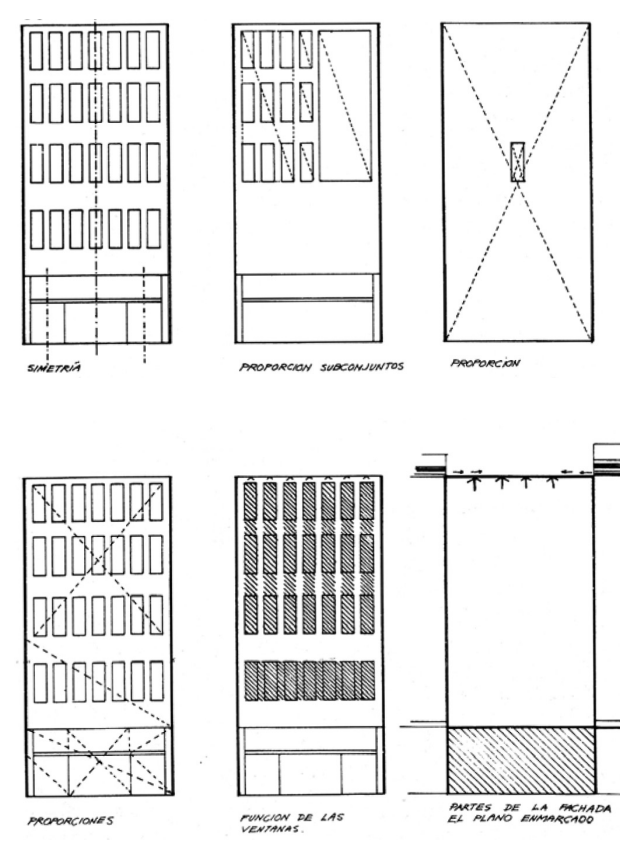

1 Serie gráfica ilustrativa de distintas decisiones y maniobras compositivas que actúan y maniobras compositivas que actuan
simuláneamente yuxtapuestas y condensadas

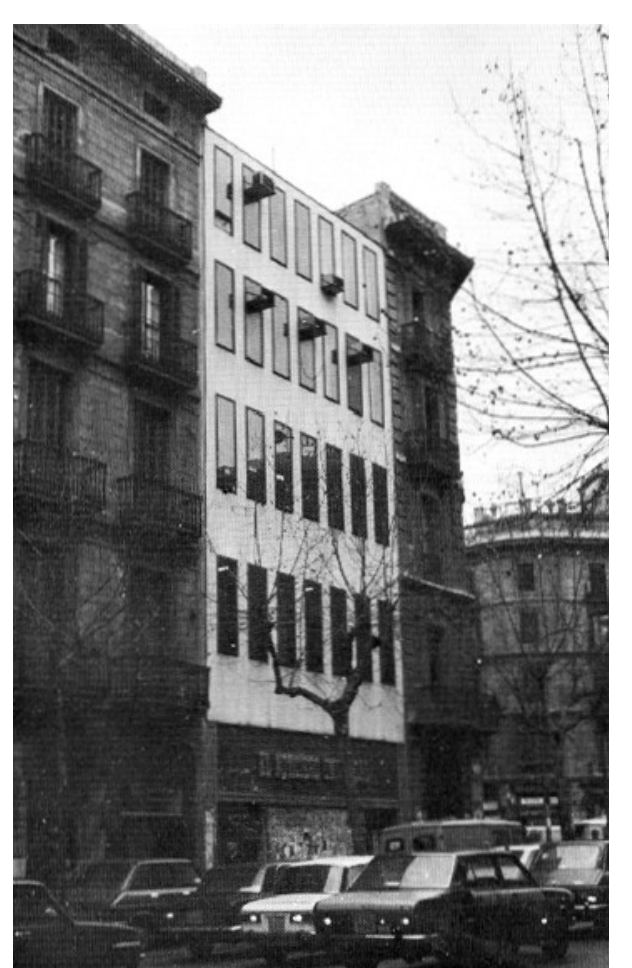

\section{Poética y Arquitectura Sostres y su Noticiero Universal}

\author{
Coque Bianco
}

Este trabajo del profesor Coque Bianco pone en evidencia el interés del análisis de edificios arquitectónicamente relevantes, cuando este análisis se hace adentrándose en la naturaleza arquitectónica del edificio.

Fue hecho dentro del cursillo "Poètica i Arquitectura" en el curso 1979-1980, cursillo a partir del cual escribí el libro "Poètica i Arquitectura".

\section{El Noticiero Universal. 1963-1965}

Se trata de un edificio poco analizado y mal conocido, que paradójicamente ha despertado los halagos y la admiración de los allegados a nuestro mundo arquitectónico pero casi siempre desde posiciones oscurantistas, incapaces de desvelar sus claves y su aparente hermetismo.

Las razones de ello pueden encontrarse en la peculiar situación fronteriza del lenguaje usado por Sostres para fabricar una obra que se ubica entre la adaptación y la transformación del medio en que se inserta (en un sentido más amplio que el exclusivamente físico). También hay que reconocer que su propia carga poética es más fácil de intuir que de reflexionar $y$, en este sentido es ineludible dejar de referirnos a la personalidad tan atrayente como crítica, tan compleja como escéptica de su autor. Uno de los síntomas de este extraño "desinterés reverente" por la obra del N. U. es la inexistente conservación de los planos originales que hubieran servido para descubrir el proceso gráfico-proyectual como pista poética seguida en nuestro caso. (Ni el FAD ni el COAC, ni el propio periódico los poseen). E material utilizado para este análisis ha sido recogido personalmente de visitas al edificio y de un levantamiento in situ. También de diversas publicaciones.

Es interesante hacer un repaso descriptivo del edificio previo a su análisis pormenorizado. Es un edificio destinado a albergar las oficinas y talleres de un periódico como ampliación de su antigua sede. La nueva construcción ocupa una parcela entre medianeras correspondiéndose en alzado a cada una de las plantas del edificio vecino.

La arquitectura que le rodea responde básicamente al programa residencial tradicional del ensanche barcelonés incluida la del edificio preexistente que ha sufrido un cambio de uso como tanto otros en este enclave.

La planta tipo original está libre de elementos estructurales y particiones divisorias. La planta baja posee un mínimo y claro intento ordenador desde la puerta principal hacia el núcleo de comunicación vertical. La fachada interior es un muro cortina que ventila a un patio propio, sin comunicarse con el patio central de manzana.

La fachada principal es un plano sin salientes $\mathrm{ni}$ retranqueos de ningún tipo y cuyas 28 ventanas iguales se disponen en cuatro bandas horizontales. La parte baja de esta fachada tiene un tratamiento de materiales considerablemente distinto a la parte superior.

Esta fachada tiene independencia constructiva aunque la disposición de las ventanas sufre variaciones para adaptarse a las distintas alturas libres entre forjados.

\section{La fidelidad al lugar}

a primera cualidad por apuntar de la actuación de Sostres quizá sea la fidelidad a la idea urbana del trazado de Cerdá. Aquella "línea definida con estilete" merece por parte de Sostres un gesto análogo. La proyección planimétrica del plano de fachada se corresponde exactamente con la anterior.

La línea de Cerdá es una idea, no implica un estilo. Su traducción poética en el N. U. la convierte en una membrana tensa donde predomina menos su espesor que su laminaridad. Su proyección es otra línea como condición de adherencia al plano de Cerdá. La palabra plano en el Plan de Cerdá y la palabra plano en la arquitectura de Sostres aquí son coincidentes. Así el edificio parece ligarse no tanto al ensanche construido como a esa idea análoga de lo que la retícula Cerdá pudo llegar a ser. Pero también posee todas las características de fidelidad reinterpretativa de la arquitectura de los Maestros de obras en la primera fase del ensanche. Atributo ligado al interés de respetar lo que se había dado en llamar "las preexistencias ambientales".

Es el propio Sostres que afirma en relación al paisaje natural urbano que... "la problemática gira alrededor del intento de hacer posible una compatibilidad entre conservación y transformación a través de una nueva metodología y de una nueva actitud. Para el arquitecto, lo que básicamente importa es aquilatar en qué proporción los cambios operados en los valores visuales podrán afectar negativamente el ambiente humano"... y agrega... "para llegar a una armonía y articulación de todas las alteraciones con el ambiente total, es necesario considerar cualquier tipo de construcción como simples objetos en un vasto espacio. Es frecuente que muchas obras de arquitectura, excelentes en sí mismas, se conviertan, en relación con la preexistencia ambiental, en puras abstracciones, sin ningún género de articulación con todo lo que les rodea"..

El edificio del N. U. es un volumen arquitectónico que, como atributo urbano positivo, posee la capacidad suficiente para "cubrir un vacío" y restañar una herida mediante una operación cicatrizante, utilizando mecanismos sencillos y obvios, que son seleccionados analógicamente tras un profundo proceso de reflexión sobre el repertorio de sugerencias de la arquitectura de la ciudad preexistente:

-la primacía de la planaridad de las fachadas -la escala habitual de las plantas bajas -la proporción de las aberturas

-la significación de la línea de remate

-el trabajo tradicionalmente tensional y estático del muro

Se trata de una condensada selección de rasgos fundamentales, nunca de anécdotas, y es este procedimiento selectivo lo que permite poner en práctica las maniobras básicamente reinterpretativas, innovadoras y creativas.

No se intenta la copia literal ni la creación de un nuevo arquetipo, sino la reelaboración de lo esencial del contenido de lo que se selecciona como materia de sugerencia oportuna.

En este sentido es Sostres que manifiesta: "queda mucho por hacer al arquitecto, aún dentro de esta época indiferenciada y poco brillante. Las exigencias de la civilización imponen nuevos deberes, y ahora como siempre, conviene aquilatar debidamente los límites de su propia responsabilidad. Adivinar en cada momento cuáles son los cabos que debe atar, y dónde y cuándo su oportuna intervención puede coordinar energías y posibilidades dispersas"...2

\section{El edificio es la fachada}

Antes de pasar al estudio específico de la fachada como elemento arquitectónico, que se vuelve tema central de análisis, es necesario hacer algunos comentarios sobre la planta y la sección.

La organización de la planta baja demuestra la intención de sugerir un itinerario elemental desde la ubicación de la puerta de entrada al edificio hasta la encrucijada con el eje de incidencia del núcleo vertical. Este recorrido se realiza a través de un primer recinto de transición entre la calle propiamente dicha y el interior. Traspasado este umbral aparecen una serie de elementos que sirven de referencia para ordenar el itinerario: 
-el mostrador articulado

-la diferenciación de pavimentos

-el desarrollo de la luminaria corrida que juega desde su

incrustación en el falso techo como indicador de dirección

Así, llegamos a un distribuidor virtual situado en el eje geométrico de la planta y a partir del cual se tienen tres opciones:

a) Continuar en forma recta hasta el fondo de la planta b) Enfrentarse al puesto de información

c) Dirigirse al nuevo ámbito de espera y comunicación

flanqueado por la escalera y el ascensor.

El análisis compositivo y dispositivo de planta, sección y alzado se vuelve sorprendente al descubrir que, por debajo de una coherente distribución espacial y disposición de elementos, subyace una estructura de líneas, formas y proporciones que corresponden a los principios de la geometría armónica pura. (...)

Finalmente, es la fachada la que puede leerse como fruto de un sistema combinatorio de cuadrados y rectángulos que, al unirse, determinan nuevos rectángulos de proporciones idénticas a las iniciales. Las diagonales de la serie de rectángulos así obtenidos trazan una red de líneas perpendiculares sobre la lámina de la fachada.

Las tres bandas superiores de ventanas quedan inscritas en un cuadrado, mientras que la banda inferior con sus respectivos huecos y macizos lo hace en un rectángulo. Esta visualización armónica refuerza la lectura de esta banda inferior de huecos como la más separada e independiente jugando un importante papel en la escala del edificio. En la parte baja de la fachada aparece la posibilidad del análisis armónico con la aparición de cuadrados y rectángulos áureos en correspondencia con las subpartes de llenos y vacíos.

Toda esta referencia a la proporción armónica pone en evidencia una intención ordenadora producto de una voluntad matemática al servicio de la más justa composición y como paso intermedio y necesario del ritmo al encantamiento.

4. La fachada. Aparición de elementos de la tradición arquitectónica

Podemos afirmar que existen dos tipos de decisiones que actúan sobre la composición de la fachada: aquellas que son aplicación de elementos de la isotopía "arquitectura tradicional" y aquellas que podemos denominar como elementos nuevos. (3)

En el primer caso, los más destacables son:

a) La disposición simétrica de los huecos en relación a los llenos de tal forma que el eje de la composición coincida con la tira central de ventanas, atribuyendo a ésta un papel decisivamente integrador. (...)

b) La disposición axial de los huecos y llenos de la planta baja cuyos planos laterales (ventana-escaparate y puerta principal) permanecen como alas retrasadas equivalentes con respecto al lleno perfectamente centrado en el eje de simetría principal.

c) La elección de las ventanas verticales, que insertadas en el muro connotan inequívocamente que éste cumple tradicionalmente funciones estáticas.

d) El estilo de tratamiento más bien "rústico" o "doméstico" de la planta baja que contrasta con el elaborado "tecnologismo" del plano superior, y que connota como basamento del edificio, enfatizando su ligamen con la tradición de uso de los bajos del Ensanche.

\section{La fachada. Aparición de elementos nuevos}

a) La autonomía del plano principal de la fachada que se pone de manifiesto a partir de su lógica constructiva, de su independencia funcional con respecto al programa interior y a la disposición modular de las series de aberturas semejantes.

Es importante ver como las diferentes alturas de los antepechos interiores de ventanas están más definidos por una intención compositiva exterior que por razones de orden funcional interno.

Uno de los efectos de las aberturas es proporcionar una referencia a la escala humana. La impresión de serenidad basada en la igualdad de lo que sucede en cada planta. Pero, al mismo tiempo, su función compositiva se transforma en relación con las diferentes dimensiones parciales de las bandas horizontales de los "lenos".

b) La carencia de cornisa como remate y la aparición en su lugar de una mínima línea de acabado especula como traslación metonímica de la presencia contigua de las cornisas de los edificios adyacentes. La presencia de las mismas tiende a ser leída y "sentida" con una intención dinámica de cierre de plano, provocando una línea de tensión que es la propia del final superior de la fachada. (...)
La colocación totalmente enrasada de las ventanas con el plano tiene el senti do de provocar una especie de disolución de límites en tre abertura y plano murario. (...)

c) La resolución metafórica del tipo de ventana escogido con relación a la tradicional abertura del edificio residencial del ensanche barcelonés funciona como referencia integradora. (...)

La colocación totalmente enrasada de las ventanas con el plano tiene el sentido de provocar una especie de disolución de límites entre abertura y plano murario. (...)

d) La percepción de que la fachada posee partes diferenciadas por la diversidad de tratamientos y por el uso de elementos singulares que sirven de transición entre las partes y que en el caso del plano principal recomponen un marco que acaba por redefinir su propia identidad. Estos elementos son:

-la banda horizontal intermedia que se lee como apeo y transición entre la planta baja y el plano superior -las juntas metálicas que remarcan la líneas de medianería

-la "presencia virtual-carencia de hecho" del remate tensiona

e) El interés por la reiteración de elementos semejantes, la misma abertura repetida exactamente 28 veces sin excepciones, y la búsqueda de la modulación que se explicita también en el despiece de la piedra artificial que reviste el plano. Estas decisiones aseguran el tono antiretórico, uniforme y repetible, en cierta forma anónimo, severo, exacto, clásico, de la fachada.

f) La innovación tecnológica conceptual que supone la decisión de construir la fachada como "forjado cerámico vertical" convenientemente armado, que permite la sustitución de las piezas de relleno por los vacíos cuando resulta necesario, facilitando el camino de la última composición.

Esta alternativa de orden constructivo supone una gran carga reflexiva y profundo vigor técnico, siendo perfecta mente coherente con el sentido autónomo de la fachada y con su expresión simbólica

g) La lectura de la fachada desde el interior nos permite interpretar que su independencia significa libertad de disponer de ella misma en toda su amplitud. La planta puede ser subdividida pero al permanecer libre y abierta se recupera a través de la fachada esta idea del paisaje urbano ordenado y modulado, lo contrario al caos en toda su magnitud.

\section{Un edificio moderno en el Ensanche}

\section{Carles Martí Arís}

Publicado originalmente en la sección de Arquitectura de El Noticiero Universal el 4 de noviembre de 1980, con motivo del decimoquinto aniversario de la construcción del edificio.

- antas veces hemos denigrado la destructiva intromisión de la moderna arquitectura especulativa en el viejo Ensanche de Barcelona, que hemos llegado a pensar en la imposibilidad de intervenir en él correctamente con los recursos de la arquitectura de nuestro tiempo. Sin embargo, algunos (pocos) edificios desmienten categóricamente esta suposición. El Noticiero Universal (1963-65) de Josep $M^{a}$ Sostres pertenece a esta pequeña lista de excepciones. (Otros ejemplos, de las dos últimas décadas, podrían ser: las viviendas del cruce CaspeRoger de Flor, de MBM; el edificio de la calle Rosellón no 152, de E. Donato, de 1964-66; la escuela I.P.S.I. en Borrell $n^{\circ} 243$, obra de Benedito-Llobet-Mateos, de 1975-78;... y pocos más).

Pero, ¿por qué es importante el Noticiero Universal, siendo un edificio tan poco espectacular, tan escasamente llamativo? ¿A qué se debe la fascinación que ejerce sobre las recientes generaciones de arquitectos? La respuesta tal vez no sea ajena al hecho de que "El Noticiero" surge como ampliación de un edificio existente (el situado en el chaflán de Lauria-Diputación), ejemplo típico de la arquitectura de los maestros de obra barceloneses de finales de siglo pasado y al hecho que Sostres, al afrontar el proyecto, se sirve de los mismos principios arquitectónicos que guiaron el trabajo de aquéllos: tensa valoración del plano de fachada, cuidada proporción de los vanos, inalterable lógica constructiva, gusto por la modulación.

Portada de El Noticiero Universal (4.11.1980) v

Sostres enfrenta los requisitos del problema (altura decreciente de los pisos por ajuste al edificio contiguo, fachada muy perforada por exigencias del uso interior del espacio, etc.) a una precisa elección compositiva: la voluntad de manejar un solo tipo de ventana cuya proporción se aproxime a la de los balcones del Ensanche. Los temas que caracterizan al edificio, como las series de siete ventanas, la progresión ascendente del ritmo de las bandas horizontales o la separación perceptiva de la planta baja, resultan "necesariamente" del desarrollo lógico de aquel enfrentamiento.

El mérito del arquitecto consiste en hacer jugar a su favor esta serie de datos y acotaciones, convirtiéndolos en disciplina formal del proyecto. El resultado parece obvio y elemental pero el mecanismo compositivo puesto en marcha para lograrlo es de una complejidad insospechada. Lo que ocurre es que, como en toda verdadera obra clásica, el esfuerzo ha sido capaz incluso de borrar sus propias huellas.

El edificio de "El Noticiero" adquiere su auténtico relieve al confrontarlo con tanta arquitectura gesticulante y afectada como padecemos. Sostres, al interpretar con un lenguaje actual los temas esenciales de la primera arquitectura del Ensanche Cerdá, logra un objetivo aún más ambicioso: establecer un nexo, un hilo de continuidad, con los grandes momentos de nuestra arquitectura (desde el románico hasta el racionalismo) y una comunión con la actitud severa y el pulso riguroso que los ha presidido.

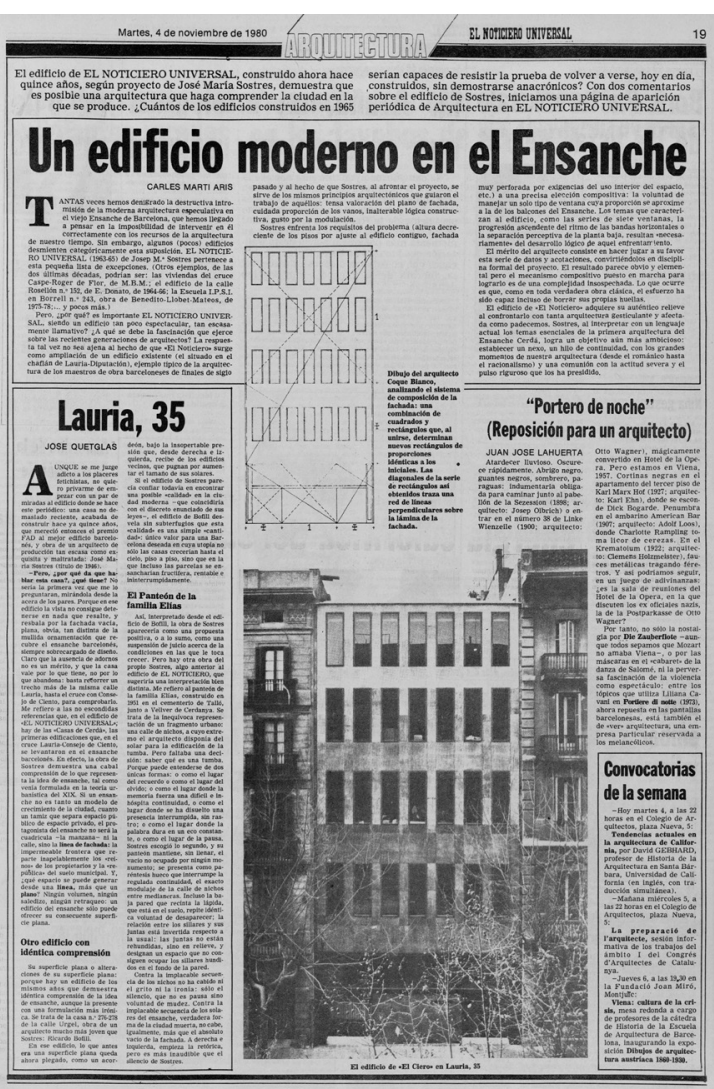




\section{La fachada. Espejo del alma}

Entre los diversos significados aristotélicos de mímesis se puede aplicar al N.U. aquel que hace mayor énfasis en el sentido de recreación. El N.U. es evidentemente algo más que una copia y si bien connota una iteración productiva de otras arquitecturas, adiciona valores específicos que lo distinguen. Siendo el resultado de una praxis como acción reflexiva con un objetivo final y evidentemente vinculada a una elección de temas reelaborados. (...)

El elemento arquitectónico ventana es un hallazgo fundamental en la arquitectura del N. U. Se convierte en clave concentrada del mensaje.

Para comprender adecuadamente su significado debemos saber que implica un "desplazamiento" una dependencia respecto de la semántica residual de la ventana tradicional. Su forma, dimensiones y proporciones análogas, su disposición seriada y reiterada, su agrupamiento en cadenas semejantes de siete unidades. La manera combinatoria de relación proporcional con el muro. Son todas condiciones a su especialísima significación compositiva.

En este sentido, recuperar la ventana vertical y disponer de ella en estas circunstancias significa que estamos en el caso opuesto de la fenêtre en longueur (que al sustituir la sucesión de ventanas verticales modifica la fachada de tal manera que la eliminación de los elementos estáticos) y también muy lejos de la ventana aislada tradicional que usa Le Corbusier como trou dans le mur (donde la transformación es inversa pasando de elementos en serie a elemento singular).

El carácter formal del edificio y su expresión simbólica se alterarían sustancialmente si variásemos su tamaño y su situación. Sabemos que un edificio nunca equivale a la mera suma de sus partes. Entre las lecturas posibles de la fachada está la que se realiza a partir de un recorrido exterior direccionado en coincidencia con la calle. La visión lateral del plano resalta la capacidad de adherencia a la arquitectura circundante y de encaje perfecto en la manzana. Invita a la percepción de la manzana en su totalidad a través del desplazamiento del espectador que la recompone en el tiempo y que se identifica a suvez con el espacio urbano. Sin embar existe un rido que es de enfrentamiento con la fachada. $Y$ esa frontalidad revaloriza la autonomía de la misma, su simetría, sus proporciones, sus detalles.

Este recorrido exterior no es un itinerario tipo "promenade architecturale " que nos introduciría dentro de la arquitectura; en todo caso, se trata de un itinerario urbano que nos reintroduce en la ciudad, en su propia coherencia espacial, y es aquí donde se descubre la intención revitalizadora del espacio urbano en la fachada del N.U. Su propia entidad nunca es privativa sobre las coordenadas integradoras y adherentes a la ciudad. Es un resultado de ellas.

La fachada del N.U. es un espejo del alma. No como noción física que refleja lileralmente una imagen análoga. No es un espejo sensible, es una creación intelectual. El valor de esta metáfora podría quedar mejor ilustrado si decantáramos la doble acepción del término reflexión. El espejo que refleja y es reflejado. El espejo que es producto de una reflexión y que, a su vez, invita a reflexionar. Ambas imágenes ambivalentes son claves intelectuales de interpretación. Este espejo refleja el alma, la esencia de la arquitectura de los maestros de obras del ensanche barcelonés pero también el alma de la arquitectura de los maestros del movimiento moderno. Este espejo nos hace reflexionar básicamente sobre el lenguaje utilizado en tan atractiva síntesis de ambigüedad y también en su propio valor de traslación metonímica de otras arquitecturas aquí representadas y de los signos hasta aquí desplazados. En este sentido creemos descubrir la actitud secreta que esconde la obra descubrir la actitud secreta que esconde la obra
como producto de un procedimiento iconográfico muy amplio y complejo. (...)

A propósito del quehacer poético, es oportuno recordar la propuesta de Maldonado que sugiere que el área de la intuición pura debe basarse sobre un conocimiento de las soluciones dadas en el pasado a problemas parecidos, y que la creación es un a problemas parecidos, y que la creación es un proceso que consiste en adaptar a las necesidades
del presente formas derivadas, bien de necesidades pretéritas, bien de las ideologías estéticas del pasado. $Y$ es el propio Sostres quien hace suya la siguiente declaración de principios de J. M. Richards..."en arquitectura no es necesario que cada uno haga su propia revolución para evitar así el ser calificado de plagiario; ya que el edificio debe ajustarse a un destino concreto, es conveniente que el arquitecto disponga de una serie de modelos debidamente experimentados para integrarlos a su proyecto. La elección adecuada y el tratamiento de la composición pueden, por sí solos, distinguir tal acto del simple plagio de las formas creadas por los innovadores, los cuales periódicamente proporcionan nuevas ideas y direcciones a seguir"..

Y él mismo agrega... "la verdadera obra de arte nace de un acto selectivo de autolimitación, y éste es un buen camino para llegar a la perfección en términos artísticos"... La fachada del N .U. no pretende ser una actuación arquetípica. En todo caso, debe apreciarse en la línea del entendimiento normativo postulado desde una posición de adelantado historicismo.

Entendemos la validez histórica de una obra por su capacidad de reflejar otras obras con valor histórico. Historicidad que se halla en el polo opuesto de las obras carentes de ese valor que del despiste cultural o del coqueteo con la moda de turno, incapaces de asumir un carácter crítico y de turno,
creativo.

EI N. U. cristaliza una especie de "saber histórico" al transformar los signos neutros heredados del lenguaje de la arquitectura en signos expresivos. Procedimiento realizado a través de una utilización apropiada de ese lenguaje, con capacidad para subvertir sus valores mediante una praxis concreta.

(1) Op. Cit. "Paisaje y Diseño". Josep María Sostres. Pub. en "Cuadernos de Arquitectura" núm. 64, 1966.

(2) y (4) Op. Cit. "Creación Arquit ectónica y Manerismo". Josep

is de acuerdo con Reichlin como isotopía "toda iteración de una unidad linguística"

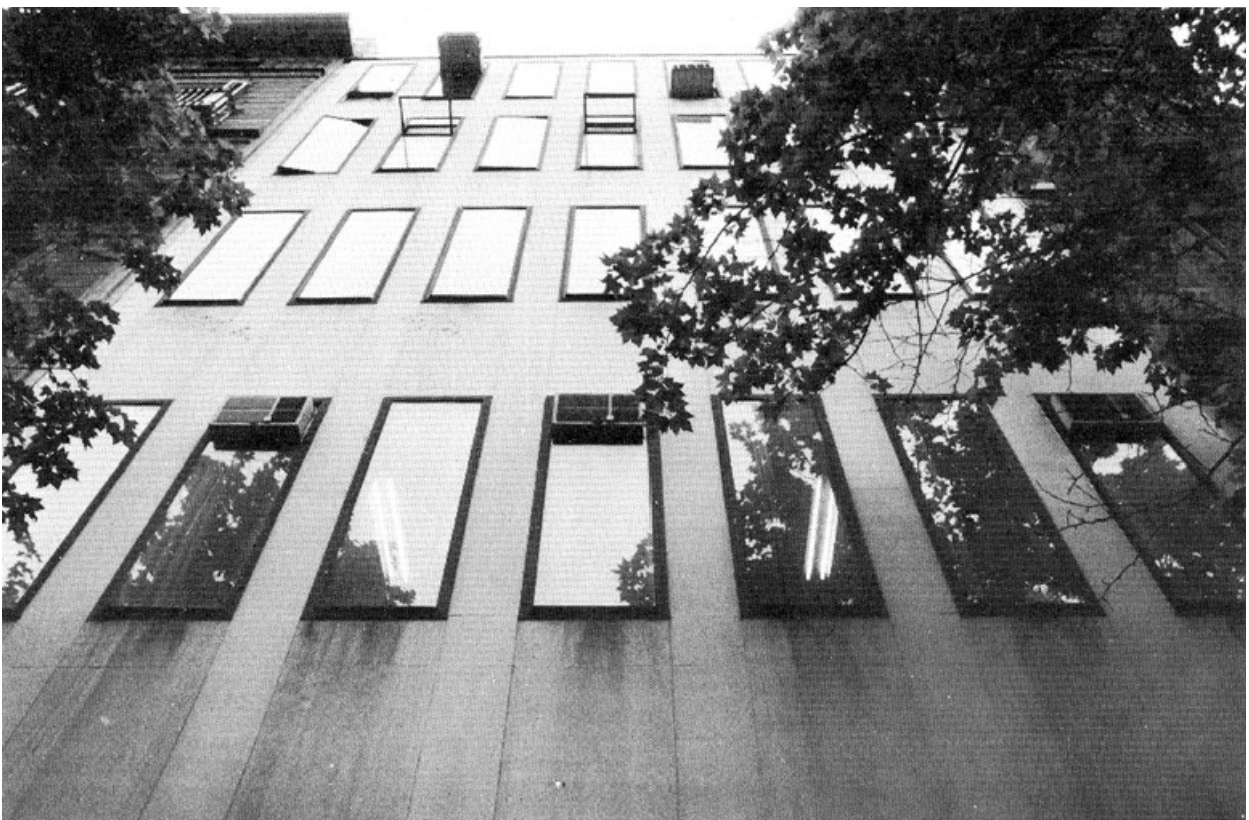

\section{Doctores en proyectos}

\author{
Alberto Peñín \\ DOI: 10.5821/palimpsesto.15.4814
}

L n 2011 y como consecuencia del Plan Bolonia, e cambio de normativa de los cursos de doctorado plazo máx universidades españolas limito a cinco años iniciadas con legislaciones anteriores. El llamado 'decreto Gabilondo', ha producido durante el curso académico 20152016 una oleada sin precedentes en la defensa de trabajos de doctorado, que ha llegado a saturar el funcionamiento del sistema en la conformación de tribunales, informes, etc. Más allá de alguna reseña periodística, son escasos los estudios, no ya que analicen contenidos, aportaciones, impactos, calificaciones, sino tan solo que pongan sobre una misma mesa el conjunto de tesis elaboradas. Este vacío también se da en el campo de los proyectos arquitectónicos, ya de por sí permanentemente preocupado por la definición de su propio ámbito de investigación. ¿Qué es investigar en arquitectura?, nos preguntamos recurrentemente, también en esta revista. Esta proliferación de trabajos, causada además por otras razones como la falta de trabajo o el acceso de otro tipo de doctorando sin vínculo con la carrera académica del que hablaremos, constituye probablemente una buena oportunidad para, si no resolver el 'enigma', sí constatar sobre qué se investiga.

Con esta intención nos hemos aproximado a distintas Escuelas de Arquitectura españolas públicas -con respuestas desiguales ${ }^{2}-$ y hemos recurrido en otros casos a sus propios registros digitales. Como resultado presentamos aquí una primera fotografía de las tesis doctorales leídas en tres de ellas que nos parecen suficientemente representativas; Madrid, Barcelona ${ }^{3}$ y Valencia, que aparece íntegramente publicada en la página web de la revista ${ }^{4}$. Solo su número y el enunciado y puesta en común de sus títulos aportan datos relevantes.

Empezaremos por la cantidad de trabajos realizados: desde 2015 y hasta febrero de 2016, fecha de caducidad fijada por el decreto, se ha leído en Valencia un número de tesis que supera el $40 \%$ del número de profesores del departamento (36 frente a 89) y en Barcelona más del 50\% (61 frente a 115). En Madrid, para un período de tiempo incluso más reducido, dado que se corresponde con el curso académico que se inicia en septiembre de 2015, han sido casi el doble las tesis, 132, que los profesores de su departamento de proyectos, también como en Barcelona, que superan el centenar. Son tasas altas, en las que destaca la muy elevada en el caso de Madrid, concurriendo probablemente numerosos factores; desde el prestigio del programa o el especial interés por la investigación arquitectónica de la Escuela, hasta un adecuado porcentaje de profesores a tiempo completo para una universidad que aspira a investigar con recursos adecuados.

Las elevadas cifras reseñadas no solo son un indicio del interés o capacidad de las Escuelas de Arquitectura en la producción de la investigación, también pueden traslucir un nuevo perfil de doctorando, no siempre vinculado al desarrollo de su carrera académica. Un primer análisis de la adscripción de los autores de los trabajos revela que en Barcelona tan solo el 2\% de los nuevos doctores tienen un vínculo con el departamento, en Madrid ronda el $10 \%$ y en Valencia alcanza una elevadísima cifra de $20 \%$. Cruzando estos datos con los porcentajes de doctores en cada departamento obtendríamos un diagnóstico más completo de la puesta al día de las plantillas de profesores.

La segunda faceta que analizaremos en esta fotografía no es la cuantitativa sino aquella relacionada con la calidad y los contenidos de las investigaciones desarrolladas. Respecto a la primera cuestión, a falta de otros datos, parece que la tendencia al excelente "cum laude" sigue siendo mayoritaria, aunque se comience a hablar de una disminución de esta costumbre académica. La calificación de las tesis no será pues el parámetro más fiable para realizar esta valoración. Un estudio más exhaustivo debiera "monitorizar" la producción científica de estas tesis, valorando el impacto y su difusión en publicaciones especializadas en los próximos años. No es menos cierto que las posibilidades de difusión e incluso reconocimiento de esta enorme producción -en total para estos tres departamentos de proyectos 229 tesis doctoralesdisminuyen notablemente al ser los canales de publicación y premios esencialmente los mismos. Mucha producción de 